\title{
Study of the Spatial Relationship between Seed Bank and Weed Populations and the Distribution Pattern of Weeds in Corn Fields during the Growing Season
}

\author{
Esmaeil Yasari ${ }^{1} \&$ Masoomeh Gholami Golafshan ${ }^{2}$ \\ ${ }^{1}$ Asstt Prof. Department of Agriculture, Payame Noor University, I. R. of IRAN \\ ${ }^{2}$ Department of Agriculture, Payame Noor University, I. R. of IRAN \\ Correspondence: Esmaeil Yasari, Asstt Prof. Department of Agriculture, Payame Noor University, I. R. of IRAN. \\ E-mail: e_yassari@yahoo.com
}

Received: April 9, 2012 Accepted: June 12, 2012 Online Published: September 26, 2012

doi:10.5539/ijb.v4n4p101

URL: http://dx.doi.org/10.5539/ijb.v4n4p101

\begin{abstract}
An experiment was conducted in the research field of the Islamic Azad University of Karaj in 2007 to study the relationship between weed seed bank at the start of the growing season and weed populations during the growing season, as well as to study the distribution pattern of the weeds. In this experiment, seed bank sampling was carried out at the beginning of the growing season (after planting the corn crop), and sampling of the populations of weed seedlings was performed at the four-leaf stage, at the $8-10$ leaf stage, and at tussle formation, in 96 places using the networking method. Then, on the basis of the abundance of weed seeds in the soil and the seedlings germinated at different sampling stages, the relationship between seed bank and seedling populations was investigated; and it was found that there is a significant relationship between seed bank at the start of the growing season and the population of weed seedlings during the growing season. The greatest correlation $(\mathrm{r}=0.83)$ was that between Flora 1 and the seed bank, indicating that weed density at this stage (the four-leaf stage of corn) was at its maximum, and that it was the best time for weed control. Next, the field was mapped with the help of the GS+ (GS plus) software, and the isotropic and anisotropic diagrams of each of the species were plotted with the help of semi-variogarms. Results obtained showed that the distribution pattern of weed species in the field was patchy, with different species having different patch diameters. Finding the correlation between seeds and floras makes it possible to determine the best time for weed sampling and weed control.
\end{abstract}

Keywords: seed bank, weeds populations, networking method, GS plus software

\section{Introduction}

The special features of weeds, such as the large number of seeds produced, the high germination rate and the rapid establishment, the very fast growth and development, the long dormancy, the preservation of vitality, the adaptation to dissemination and distribution, and the vegetative propagation parts, have always made them very strong competitors of field crops; and today, in spite of the considerable amount of money and time spent in controlling them, they continue to damage field crops (Douglas, 1995). Distribution patterns and spatial distributions constitute an important variable in the mutual relationships between plants and affect the competition between species and their survival. In other words, the distribution patterns influence the adaptation of the species in the environment and the long term population dynamics of the populations of different species (Baker, 1989). Therefore, the concept of spatial distribution can be used to identify and understand the dynamics of weed population and to increase the efficiency of the management in weed control (Cantrell \& Cosner, 1991). Study of the distribution patterns of weeds showed that the distribution and the dispersion of weeds in a field are not random, and that weeds could be more abundant in one or several patches in the field (Benoit, 1986). Weeds are often denser in patches of the field where the conditions are more suitable for their survival (Dutilleul, 1994). The reason for the patchy distribution of weeds in a field is the mutual relationship between the biology of the weeds, the environmental conditions, and the agricultural activities carried out (Chauvel et al., 1989).

The results we obtained showed that the indeterminate distribution of weeds in a field, to a large extent, depends on incorrect measures taken in chemical and non- chemical weed control management. We used spatial statistics to plot semivariogarms which describe the spatial structure of the populations of the weeds. The maps drawn 
showed the density of the weeds and the manner of their distribution; and kriging was employed to indicate the density of weeds in areas of the field where weeds were not sampled (Cardina et al., 1995). Since weeds are concentrated in some patches in the field, the densities calculated in different places of the field are not independent from each other; that is, these densities depend on the distances between the sampling places (Cardina et al., 1995; Donald, 1994). There is a correlation among data related to each other. Therefore, the difference between samples taken from places close to each other is less than that between samples taken from places which are farther apart (Bigwood \& Inouye, 1988). Information concerning the abundance and the composition of the seeds in weed seed bank is very important in identifying the dynamics of the populations of the weeds; and the use of the information on the seed bank is very helpful and useful in predicting future weed populations (Ball \& Miller, 1989; Barralis et al., 1986). Assessment of weed seed populations in the soil is used to estimate the germination time of weed seeds and the density of weed seedlings; and it can also be used in the control and management of weeds (Forcella, 1992; Forcella et al., 1992).

Correlation coefficient and regression, which describe the relationship between the means and the variance, can be used to recognize the relationship between the weed seed bank and the future populations of the weeds (Ball \& Miller, 1989; Barralis et al., 1986; Forcella, 1992; Goyeau \& Fablet, 1982). For seed bank information to be useful and valuable in identifying weeds, in predicting weed populations, and in controlling weeds, it should describe the spatial distribution of the weeds in the field and not just indicate the means of the populations of the weeds in the field.

Cardina, in research carried out in 1996, stated that the threshold density of weeds is generally low, that the density of weeds in one patch is higher than that of the threshold level, and that sometimes the mean density of the weeds in the field may be less than that requiring control (Cardina \& Sparrow, 1996). Information on seed bank is valuable when it shows the distribution pattern of the weed populations. Information concerning the spatial patterns of weeds in the field can be used to control weeds in the best possible manner.

Analysis of the semivariogram, which is conducted on the basis of data obtained from the field, is a method that explains the difference between seed bank and the seedlings present in the field. The semivariogram states the common spatial relationship between the seed bank population and the population of germinated weed seedlings (Cardina \& Sparrow, 1996).

The goals of this project included the study of the distribution of the seed bank and the populations of weeds in the field, and also the study of the relationship between weed seed bank at the start of the growing season and the populations of the weeds during the growing season. Furthermore, by studying the trend of changes in seed bank and the flora of the weeds during the growing season, and through studying the relationship between them, it is possible to find a suitable pattern for predicting the composition and the density of weed species, to determine the appropriate time for weed control in the field, and to decide on the optimum time and the most suitable method of exercising good management with the purpose of reducing the density of the seeds present in the weed seed bank.

\section{Materials and Methods}

This experiment was conducted in the research field of the agronomy department of the agriculture college of the Islamic Azad University of Karaj in 2007. The field has a latitude of $35^{\circ}$ and $45^{\prime}$ North, a longitude of $51^{\circ}$ and $6^{\prime}$ East, and an altitude of 1313 meters above sea level. Climate-wise, Karaj is classified as a semi-arid region. The soil in the field was tested and it was found to be loamy sand with a pH of about 8 , an EC of 1.4, and an acid equivalent of 7.6. The dimensions of the field were 60 by 20 meters, and it was under a corn crop.

Land preparation operations included deep plowing with a reversible plow, two disking operations in perpendicular directions, and leveling the land. $250 \mathrm{Kg}$.h of ammonium phosphate was applied to the land as base fertilizer. To investigate the seed bank and the populations of the weeds, after the final land preparation operation, the field was divided and roped into 4 by 4 meter networks. The intersections of the networks were marked and staked and, till the end of the growing season, all samples were taken at these points. On the 14th of April, 2007, the disinfected corn seeds were planted by hand at the depth of $3 \mathrm{~cm}$. In every hill, two to three seeds were placed. After seed germination, at the four-leaf stage, thinning was carried out so as to have a density of 80000 corn plants per hectare.

\subsection{Taking Samples from the Seed Bank}

Soil samples were taken as described below by using an auger having a diameter of $5 \mathrm{~cm}$. First, after marking the sampling points, the quadrat would be on the ground in such a way that the staked point was situated in the middle of the quadrat. The sampling area was one square meter. Inside the quadrat, soil samples were taken from 
five points zero to $10 \mathrm{~cm}$ deep. The samples were then mixed together, placed in black plastic bags, and transferred to the laboratory. Next, $150 \mathrm{~g}$ of the total soil was weighed and separated. This sample was placed in silk bags (Beheshtean et al., 2007) and put in a water container in the laboratory. After several days, the soil was completely washed out and only the seeds and very small stones remained in the bags. The seeds, together with the sand particles, were dried, counted, and identified to the level of the genus using a binocular stereomicroscope. Those seeds that resisted the pressure applied by forceps and did not yield were assumed to be healthy (Forcella, 1998). Then the number of seeds counted was used to calculate the number of seeds per hectare.

\subsection{Taking Samples from the Floras}

The first sampling was conducted using a quadrat at the four-leaf stage of the corn (June 7th), and at the same points where seed bank sampling had been carried out. All the germinated seedlings inside the quadrat were identified, counted, and then eliminated. The next samples were taken in the same way at the 8 to 10 leaf stage of the corn ( 27 days after the first sampling) and at tussle formation ( 15 days after the second sampling).

The method of taking samples from the seed bank and from the flora:

The networking method:

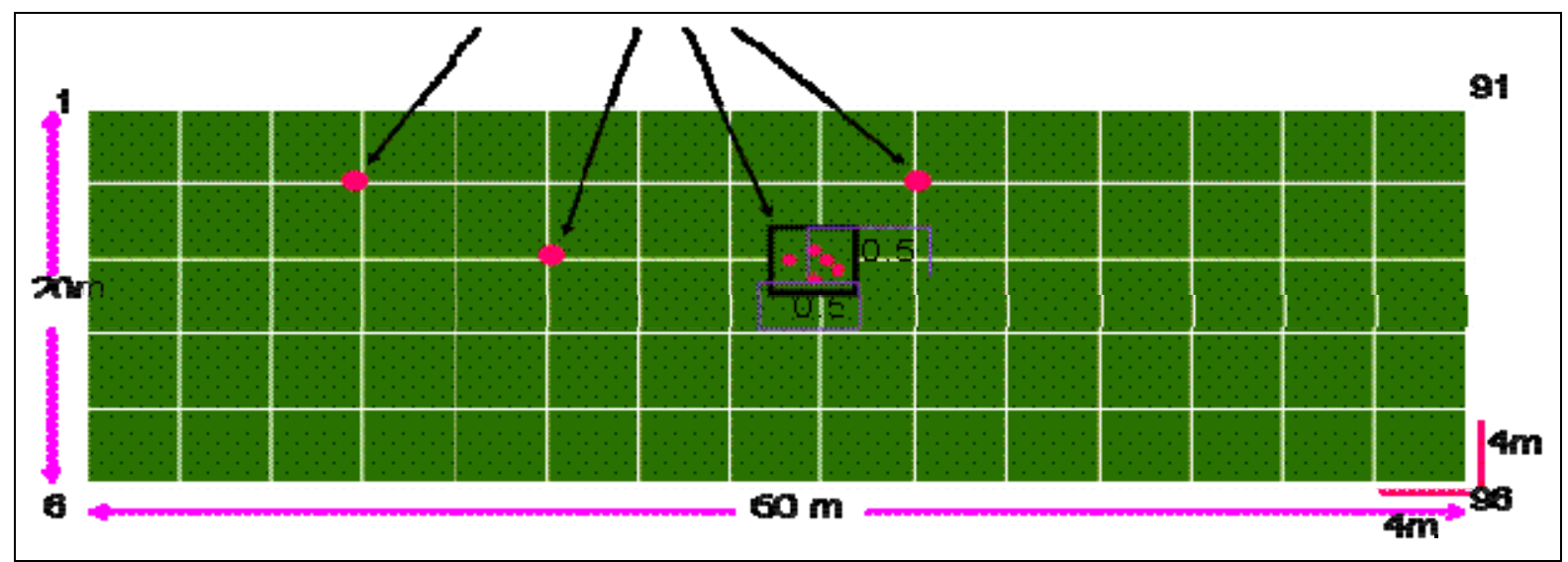

Figure 1. The sampling points

To study the spatial pattern and the distribution of weeds in the field, and in order to make an estimate of the populations of the weeds in different patches in the field (that is, for the purpose of mapping the weeds), the data was fed to the GS+ software; and this software, while making the necessary transformations for normalizing the data, drew the maps of the distribution patterns of the seed bank, of the populations of the weeds, and also of the weed patches together with their diameters in the field. The seed density and the density of weed seedlings in the areas between the sampling points (that is, the areas where no samples are taken) can be estimated by employing the Kriging method. Kriging is the method for obtaining the best possible evaluation of the areas between sampling points, and for estimating the weed populations in these areas (Cardina, 1996). We also performed data analysis on the basis of seed abundance in the seed bank, and on the basis of the abundance of weed species in the floras. 


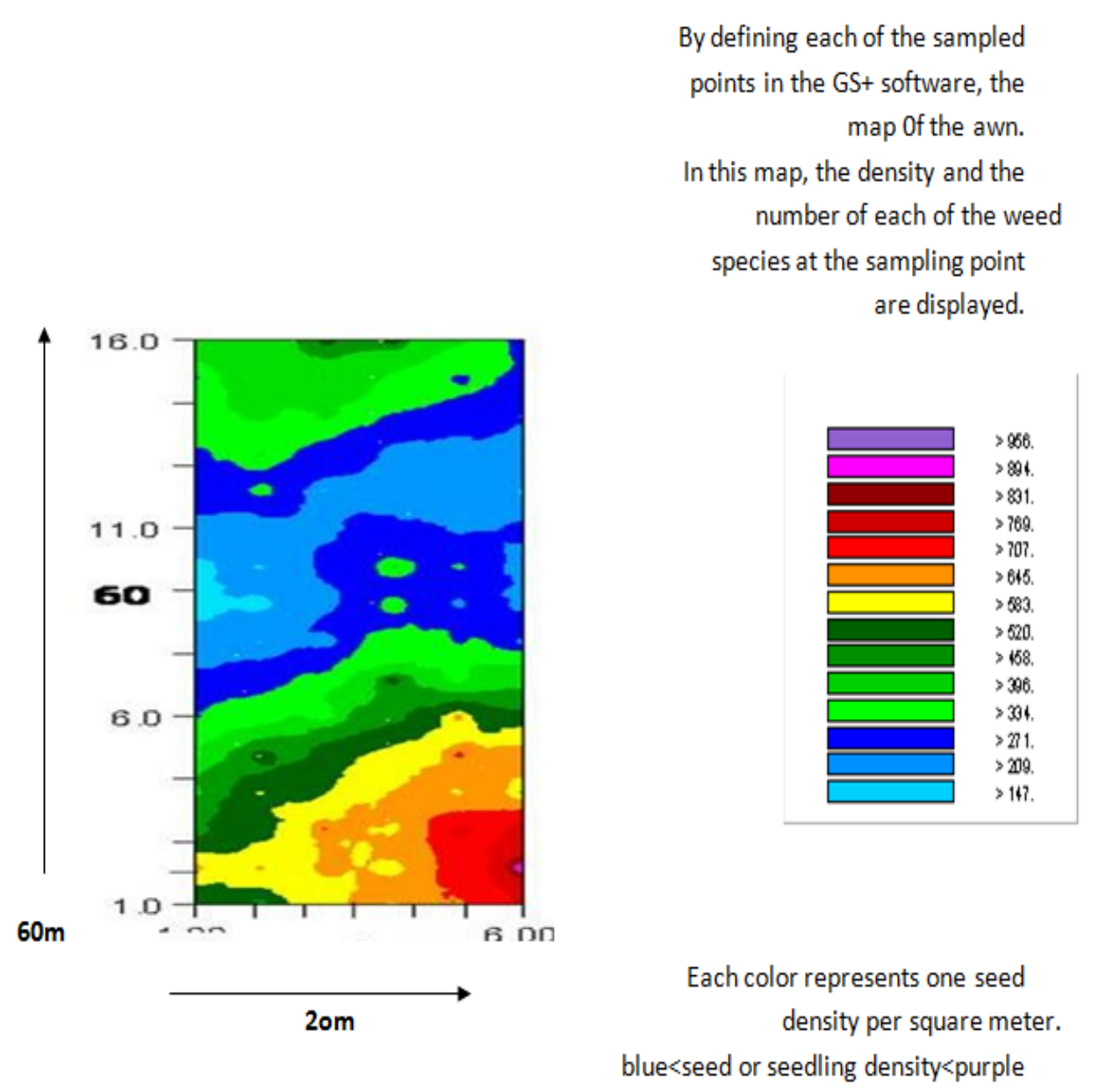

Figure 2. The map of the density and the mumber of each of the weed species

In order to obtain the distribution pattern and to calculate the diameters of the weed patches, we used the experimental semivariance formula. Semivariance is the sum of the differences between the two observations $\mathrm{z}(\mathrm{x})$ and $\mathrm{z}(\mathrm{x}+\mathrm{h})$ at two places situated in the sampling area and separate from each other.

$$
Y(h)=\frac{i}{2 N(h)} \sum_{i=1}^{N(h)}\left(Z\left(x_{I}\right)-Z\left(x_{i}+h\right)\right)^{2}
$$

Where $N(h)$ is the number of paired samples (in semivariances, samples are compared two by two), and $z$ (xi) is the first sample taken; $\mathrm{z}(\mathrm{xi}+\mathrm{h})$ is the second sampling point chosen (taking the distance $\mathrm{h}$ into account). A variograms, in fact, assesses the mean of the dissimilarity of the data at the two points $\mathrm{x}$ and $\mathrm{x}+\mathrm{h}$ as a function of the distance $\mathrm{h}$ between them; and it can be calculated for different directions of sampling (Jahangard Mohammadi, 2006). Sometimes, in calculations, some pairs of data are not separated from each other by the exact determined distance $h$; therefore, instead of a fixed distance, a range of tolerable distances must be chosen with a tolerance of plus or minus one.

\section{Result}

\subsection{Different Diagrams of Semivariance}

1) Isotropic variograms: an isotropic variogram shows the weed patch of the field only in one direction.

2) Anisotropic variograms: an anisotropic variogram shows the weed patch in different directions and with angles of 45, 90, and 135 degrees, and also when the field is under the influences of the slope, the wind direction, and the direction of water movement. 
Isotropic Variogram

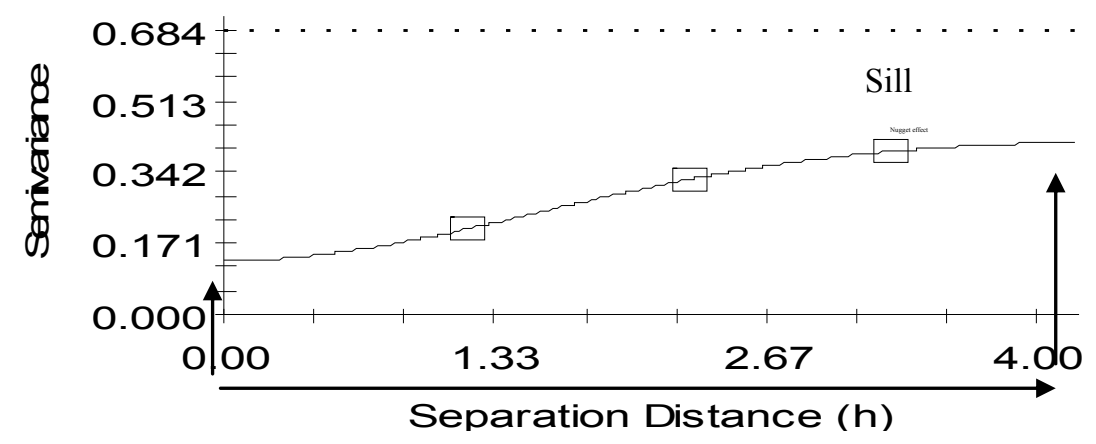

Figure 3. Representing the diameter of the weed patch with an isotropic diagram

Gaussian model $(\mathrm{Co}=0.1303 ; \mathrm{Co}+\mathrm{C}=0.4236 ; \mathrm{Ao}=2.19 ; \mathrm{r} 2=1.000 ; \mathrm{RSS}=1.127 \mathrm{E}-06)$

At the (Sill) point, the numerical changes in the semivariance are such that the intended function lacks any definite increase or decrease. The distance at which the variogram reaches a certain fixed limit, is given the name "the range". The range, in fact, shows the diameter of a patch of weeds and, beyond this range, the samples no longer influence each other, and the observed or sampled values can be considered as independent from each other. In other words, such a distance marks the limit of the spatial correlation and the variable under study. The initial distances change suddenly, and this is termed the Nugget Effect. Theoretically, the initial value of the semivariance should be zero, but it is usually more than zero, and this can be attributed to factors such as errors in sampling and to errors in the laboratory, to sudden changes in narrow ranges, and to other factors.

\section{Isotropic Variogram}

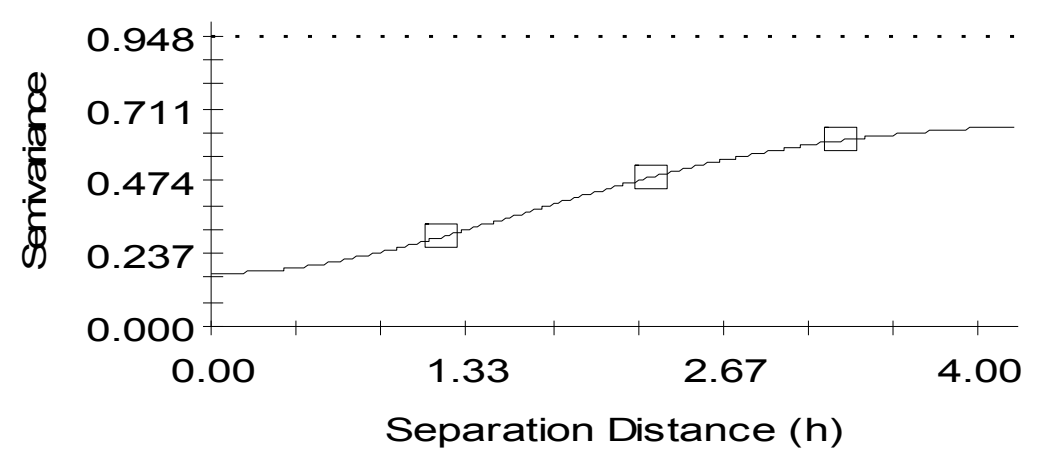

\footnotetext{
Gaussian model $(\mathrm{Co}=0.1740 ; \mathrm{Co}+\mathrm{C}=0.6730 ; \mathrm{Ao}=2.30 ; \mathrm{r} 2=1.000$; RSS $=9.779 \mathrm{E}-06)$
}

The diameter of the patch of grass weeds was 4 meters 


\section{Isotropic Variogram}

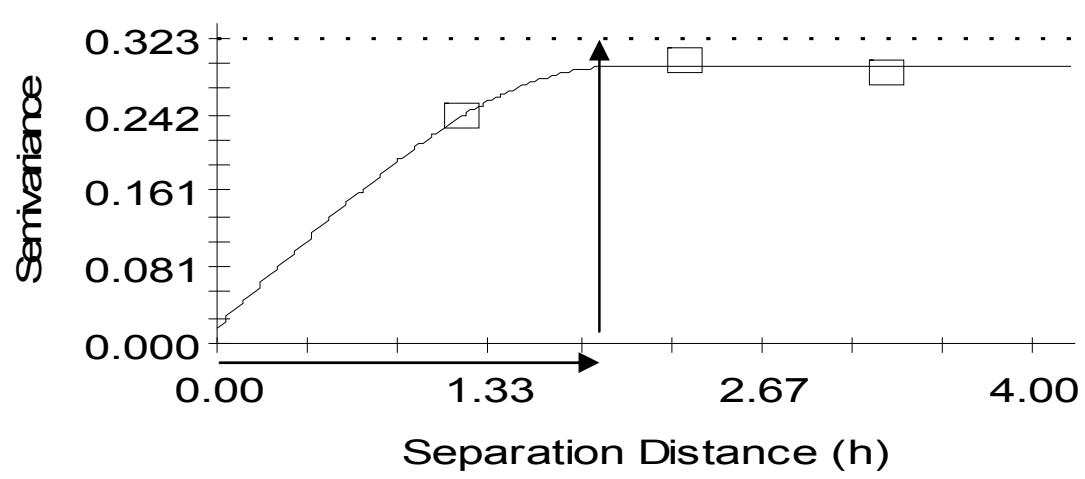

Spherical model $(C o=0.0172 ; \mathrm{Co}+\mathrm{C}=0.2924 ; \mathrm{Ao}=1.93$; $\mathrm{r} 2=0.953$; RSS $=9.197 \mathrm{E}-05$ )

The diameter of the patch of Amaranthus was 1.5 meters

Isotropic Variogram

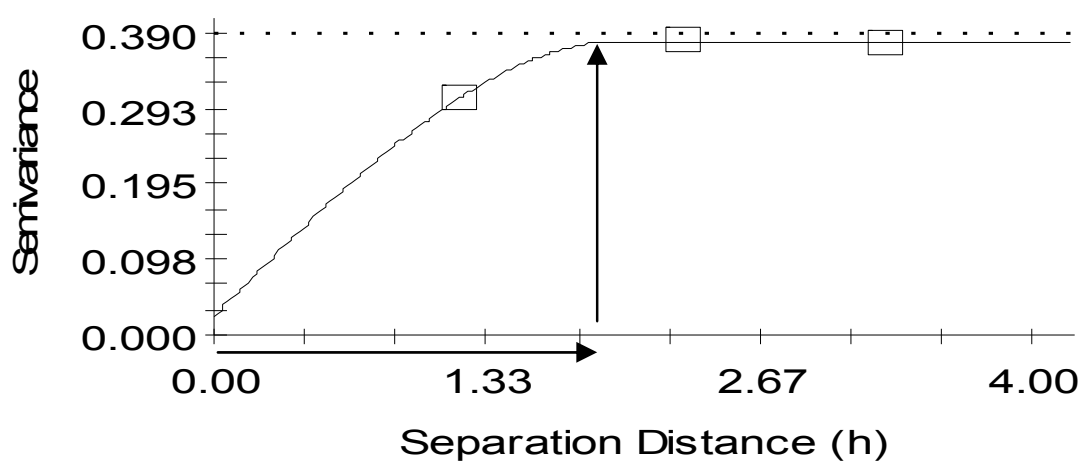

Spherical model $(\mathrm{Co}=0.0240 ; \mathrm{Co}+\mathrm{C}=0.3800 ; \mathrm{Ao}=1.99 ; \mathrm{r} 2=1.000$; RSS $=1.825 \mathrm{E}-06)$

The diameter of the patch of Portulaca was 1.3 meters

Figure 4 . The isotropic method for drawing weed patches in seed bank 
Isotropic Variogram

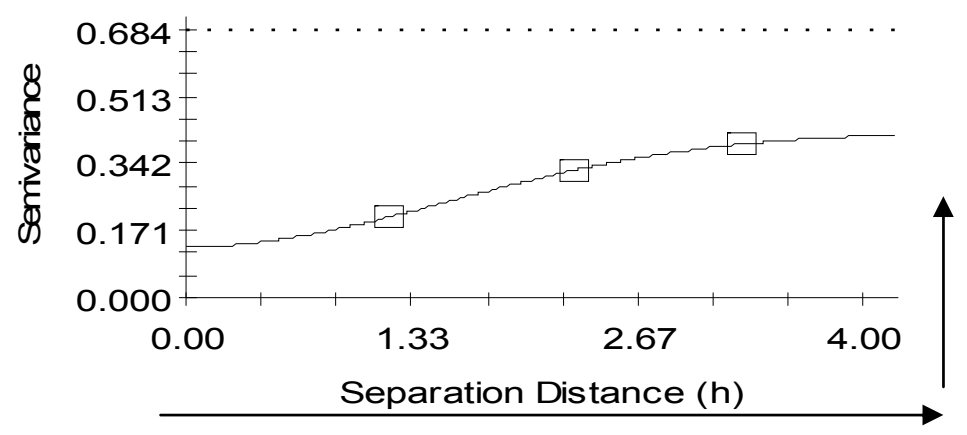

Gaussian model $(C o=0.1303 ; C o+C=0.4236 ; A o=2.19 ; r 2=1.000$; RSS $=1.127 \mathrm{E}-06)$

The diameter of the patch of grass weeds was 4 meters

Isotropic Variogram

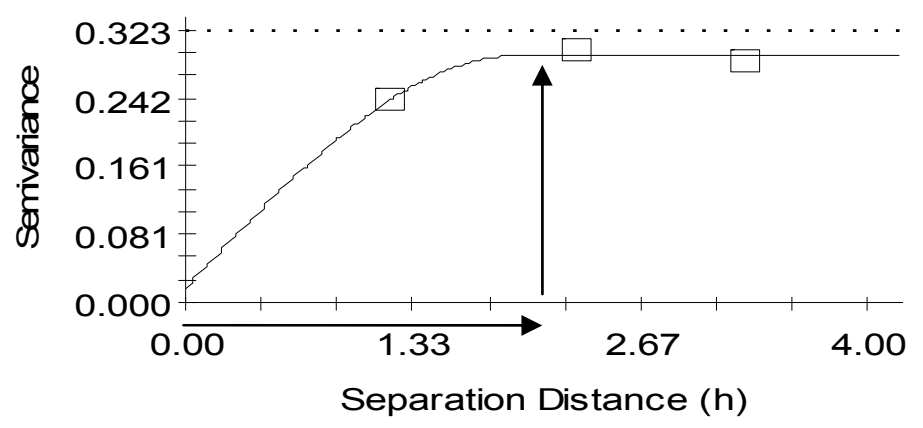

Spherical model $(C o=0.0172 ; C o+C=0.2924 ;$ Ao $=1.93 ; r 2=0.953$; RSS $=9.197 \mathrm{E}-05)$

The diameter of the patch of Amaranthus was 1.5 mete

Isotropic Variogram

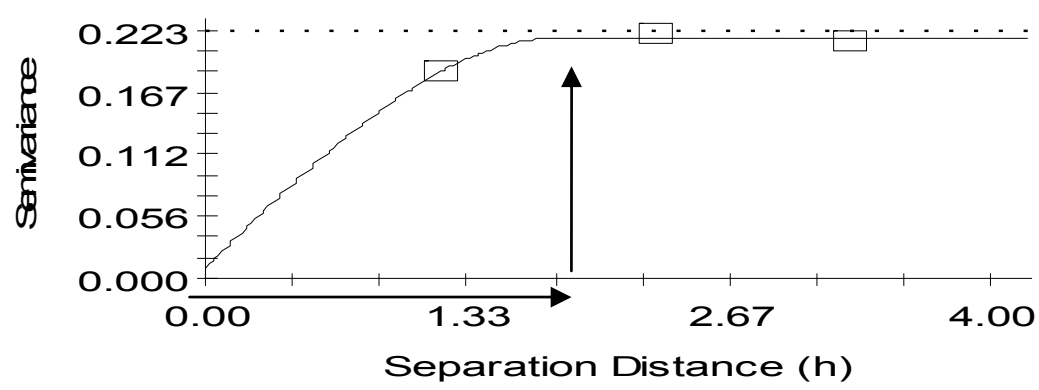

Spherical model ( $C o=0.0097$; $C o+C=0.2164 ;$ Ao $=1.79 ;$ r2 $=0.971$; RSS $=2.031 \mathrm{E}-05$ )

The diameter of the patch of Portulaca was 1.3 meters

Figure 5. The isotropic method for drawing weed patches in floras 


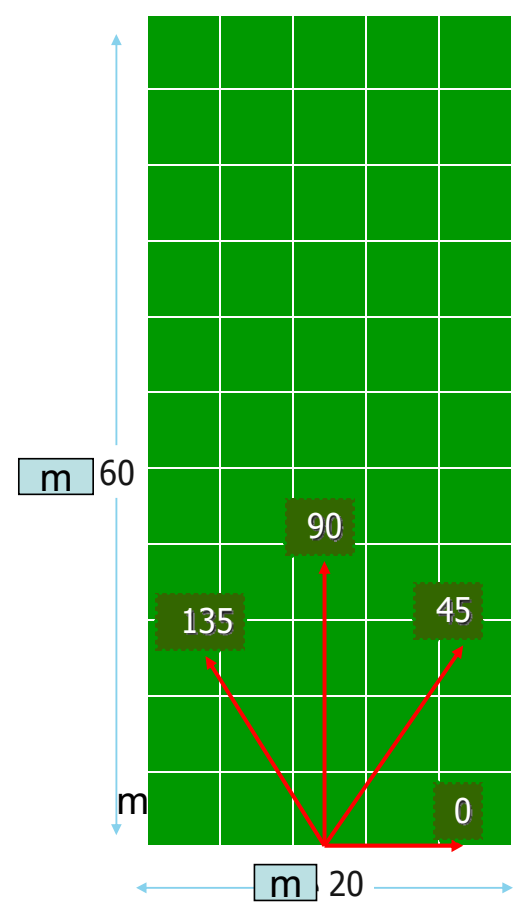

Figure 6. Anisotropic patch in the field

Generally speaking, various factors, such as the wind direction, irrigation, the direction the land is plowed, and the tillage operations, influence weed distribution in the fields. These factors can determine the direction of the distribution pattern, but their effects in this respect can be observed only when the experiment is repeated over several years so that these effects have a chance to show themselves. In our experiment, comparison of anisotropic variograms having different directions showed no differences among them, and hence we only provided the isotropic diagram which takes all directions into account and calculates it as an isotropic of the variogram.

The distribution maps for the seed bank and for the weed seedling populations were fed to the GS+ software and were compared; and the percentages of germination, which are calculated by dividing the number of germinated seedlings of each species to the number of its seeds in the soil seed bank multiplied by 100 , were obtained. Moreover, the SAS software (SAS Ver. 9.1) was used to calculate Spearman's correlation coefficient between the seed bank and the populations of weed seedlings.

In the table below, the means of weed densities in the seed bank for grass species, Amaranthus, Portulaca, Convolvulus, Xanthium, Chenopodium, and Polygonum can be seen.

Table 1. Seedlings of weed species observed at different sampling stages

\begin{tabular}{lllll}
\hline Weed species & $\begin{array}{l}\text { Sampling after } \\
\text { planting the crop }\end{array}$ & Flora 1 & Flora 2 & Flora 3 \\
\hline Grasses & 220586 & 523 & 127 & 68 \\
Amaranthus & 165960 & 382 & 25 & 17 \\
Portulaca & 131050 & 302 & 53 & 23 \\
Convolvulus & 9854 & 17 & 5 & 3 \\
Xanthium & 10879 & 21 & 8 & 1 \\
Chenopodium & 17591 & 28 & 15 & 3 \\
Polygonum & 12568 & 12 & 8 & 3 \\
\hline
\end{tabular}




\subsection{Calculating the Percentages of Germination of Weed Species}

The percentages of germination of grass weeds, Amaranthus, and Portulaca were calculated by dividing the densities of germinated seedlings to the densities of the populations in the seed bank (Table 2); and it was found that germination percentages were higher in grasses (and the populations of germinated seedlings during the growing season confirmed this ).

Table 2. Means of seed populations and means of populations of weed seedlings and their germination percentages

\begin{tabular}{llll}
\hline Weed species & $\begin{array}{l}\text { Seed bank } \\
\text { No. of seeds per square } \\
\text { meter }\end{array}$ & $\begin{array}{l}\text { Weed seedling } \\
\text { No. of seedlings per } \\
\text { square meter }\end{array}$ & $\begin{array}{l}\text { Percentage germination } \\
\text { (No. of seeds/No. of } \\
\text { seedlings) } \times 100 \%\end{array}$ \\
\hline Grasses & 220586 & 719 & $0.32 \%$ \\
Amaranthus & 165960 & 425 & $0.25 \%$ \\
Portulaca & 131050 & 380 & $0.28 \%$ \\
Convolvulus & 9854 & 8 & $0.08 \%$ \\
Xanthium & 10879 & 10 & $0.09 \%$ \\
Chenopodium & 17591 & 15 & $0.08 \%$ \\
Polygonum & 12568 & 7 & $0.05 \%$ \\
\hline
\end{tabular}

Results obtained show that percentage germination was higher in grasses and reached almost $0.32 \%$, while the lowest germination percentage was about $0.05 \%$ and belonged to Convolvulus.

Percentage germination determines the relationship between the seed bank and the seedlings. In grasses, because of the high percentage germination, the seed bank can be used at the start of the growing season to correctly predict the number of weed seedlings present in the field during the growing season. However, in species like Convolvulus which have low germination percentages, it is not possible to estimate the number of weed seedlings during the growing season, because the low densities in the seed bank do not allow it. Reports related to research carried out by Cardina also confirm this conclusion.

Table 3. The relationship between weed seed bank and weed seedling populations in the field

\begin{tabular}{lllll}
\hline Weed seed & Flora 1 & Flora 2 & Flora 3 & Total \\
\hline Grasses & $0,94^{* *}$ & $0.57^{* *}$ & $0.56^{* *}$ & $0.96^{* *}$ \\
Amaranthus & $0.63^{* *}$ & $0.14 \mathrm{~ns}$ & $0.14 \mathrm{~ns}$ & $0.64^{* *}$ \\
Portulaca & $0.61^{* *}$ & $0.042 \mathrm{~ns}$ & $0.056 \mathrm{~ns}$ & $0.72^{* *}$ \\
Total & $0.48^{* *}$ & $0.36^{* *}$ & $0.43^{* *}$ & $0.83^{* *}$ \\
\hline
\end{tabular}

Results of the table above showed that in grasses, in which germination percentages were high, Spearman's correlation coefficients were also meaningful and reached $r=0.83$.

\section{Conclusions}

In the field, we constantly face different waves of weeds; and it is important to recognize when weed seedling densities in the field are at their maximum, because by knowing this we can choose the best time for weed control so that the control can be efficient. Moreover, in future research projects, we can omit the species that had lower correlations from the sampling process to save time and money. Therefore, sampling of the populations of weed seedlings was carried out in three stages; and the results obtained showed that the first sampling, which was conducted at the four-leaf stage of the corn crop, yielded the highest populations of weed seedlings and also showed the greatest correlation coefficient between these populations and the weed seed bank (and this correlation was especially pronounced in grasses). In later samplings which were conducted at the eight-leaf and at the tussling stages of the corn crop, the weed seedlings had lower densities and the Spearman's 
correlation coefficients for later samplings gradually declined.

\section{References}

Ball, D. A., \& Miller, S. D. (1989). A comparison of techniques for estimation of arable soil seed banks and their relationship to weed flora. Weed Res., 29, 365-373. http://dx.doi.org/10.1111/j.1365-3180.1989.tb01307.x

Baker, H. G. (1989). Some aspects of the natural history of seed banks. In M. A. Leck, V. T. Parker, \& R. L. Simpson (eds.), Ecology of Soil Seed Banks (p. 9-21). New York, Academic Press.

Barralis, G., Chadoeuf, R., \& Gouet, J. P. (1986). Essai de determination de la taille de echantillon pour etude du potential semencier dun sol. Weed Res., 26, 291-297. http://dx.doi.org/10.1111/j.1365-3180.1986.tb00709.x

Benoit, D. L. (1986). Methods of sampling seed banks in arable soils with special reference to chenopodium spp. Ph. D. thesis, University of Western Ontario, London, Canada.

Beheshtean, M., Mesgaran, M. B., Rahimian, H., \& Alizadeh, H. (2007). Comparison of three methodologies for efficient seed extraction in studies of soil weed seed bank. Weed Res., 47, 472-478. http://dx.doi.org/10.1111/j.1365-3180.2007.00592.x

Bigwood, D. B., \& Inouye, D. W. (1988). Spatial pattern analysis of seed banks: an improved method and optimized sampling. Ecologh, 69, 497-507. http://dx.doi.org/10.2307/1940448

Cantrell, R. S., \& Cosner, C. (1991). The effects of spatial heterogeneity in population dynamics. J. Math. Biol., 29, 484-498. http://dx.doi.org/10.1007/BF00167155

Cardina, J., \& Sparrow, D. H. (1996). A comparison of methods to predict weed seedling population from the soil seed bank. Weed Sci. (In Press).

Cardina, J., Sparrow, D. H., \& McCoy, E. L. (1995). Analysis of spatial distribution of common Lambsquarters (Chenopodium album) in no-till soybean (Glycine max). Weed Sci., 43, 258-268.

Chauvel, B., Gasquez, J., \& Darmency, H. (1989). Changes of weed seed bank parameters according to species, time and environment. Weed Res., 29, 213-219. http://dx.doi.org/10.1111/j.1365-3180.1989.tb00861.x

Donald, W. W. (1994). Geostatistics for mapping weeds, with a Canada thistle (Cirsium arvense) patch as a case study. Weed Sci., 42, 648-657.

Douglas, D. B. (1995). Influences of tillage systems on weed population dynamics and management in corn and soybean in the central USA. Crop Science, 35, 1247-1258. http://dx.doi.org/10.2135/cropsci1995.0011183X003500050001x

Dutilleul, P. (1993). Spatial heterogeneity and the design of ecological field experiments. Ecology, 74, 1646-1658. http://dx.doi.org/10.2307/1939923

Forcella, F. (1998). Real-time assessment of seed dormancy and seedling growth for weed management. Seed Science Research, 8, 201-209. http://dx.doi.org/10.1017/S0960258500004116

Forcella, F. (1992). Prediction of weed seedling densities from buried seed reserves. Weed Res., 32, 29-38. http://dx.doi.org/10.1111/j.1365-3180.1992.tb01859.x

Forcella, F., Wilson, R. G., Renner, K. A., \& Cardina, J. (1992). Weed seed banks of the U.S. Corn belt: Magnitude, variation, emergence, and application. Weed Sci., 40, 636-644.

Goyeau, H., \& Fablet, G. (1982). Etude du stock de semences de mauvaises herbes dans le sol:Le problem de echantillonnage. Agronomie, 2, 542-551. http://dx.doi.org/10.1051/agro:19820607

Mohammadi, J. (2008). Pedometry, Geostatic Statistics. Second Volume. Pelk Publications, p. 118. 